\title{
PERSPECTIVA ARQUITETÔNICA: CONTRIBUIÇÃO AO PROCESSO DOS MEDIDORES.
}

Rogerio Penna Quintanilha

Universidade do Oeste Paulista - UNOESTE, Curso de Arquitetura e Urbanismo, Presidente Prudente, SP. Email: arq.rogerio@gmail.com

\section{RESUMO}

A pesquisa contribuiu para a discussão acerca do ensino e da prática da perspectiva arquitetônica como processo de projeto. Propõe-se uma abordagem diferente sobre o método de desenho a partir de algumas regras que são introduzidas. Baseadas em artifícios geométricos, essas alternativas buscam facilitar o ensino e a prática acadêmica e profissional do traçado da perspectiva arquitetônica.

Palavras-chave: Perspectiva geométrica; desenho geométrico; desenho de arquitetura;

\section{ARCHITECTURAL PERSPECTIVE: TECHNIQUES, APPLICATIONS AND TEACHING OF THE GEOMETRIC PERSPECTIVE IN ARCHITECTURE.}

\section{ABSTRACT}

The research contributed to the discussion about the teaching and practice of the architectural perspective as a design process. It proposes a different approach on the drawing method from some rules that are introduced. Based on geometrical artifice, these alternatives seek to facilitate the teaching and academic and professional practice of the drawing of the architectural perspective. Keyword: Geometric perspective; geometric drawing; architecture drawing; 


\section{INTRODUÇÃO}

A perspectiva axonométrica, desenvolvida inicialmente por Filippo Brunelleschi no Renascimento, tem sido uma privilegiada forma de representação projetiva arquitetônica. A possibilidade de simulação do espaço tridimensional na superfície plana através do escorço, a mão livre, com instrumentos ou ainda computadorizada, sem dúvida oferece muitas possibilidades de visualização que podem ser bastante úteis nas diferentes etapas do processo de projetação arquitetônica, dos traços iniciais à evolução do projeto e finalmente à apresentação final da proposta ao cliente.

O método tradicional de traçado de perspectiva axonométrica, no entanto, normalmente requer o auxílio de instrumentos como réguas paralelas, escalímetros e esquadros para seu desenvolvimento preciso. Além disso, requer também que o desenho seja construído a partir de uma planta baixa já definida, que deve ser desenhada em escala. A pesquisa estudou e desenvolveu, dessa forma, variações dessa concepção original que resultassem em uma aplicação mais ágil da técnica geométrica, se possível dispensando instrumentos, para facilitar sua aplicação nas etapas de criação e croquis iniciais do projeto arquitetônico quando ainda não há uma planta baixa definida.

\section{REVISÃO DE LITERATURA}

Montenegro (1999) elabora três processos diferentes para a elaboração de perspectivas axonométricas com instrumentos. O primeiro deles é chamado processo dos arquitetos, ou processo das projeções ou ainda processo de irradiação, método bastante conhecido sobre o qual não há necessidade de explicação demorada mas que está demonstrado na figura 1.

Figura 1. Método tradicional do traçado de perspectiva arquitetônica.

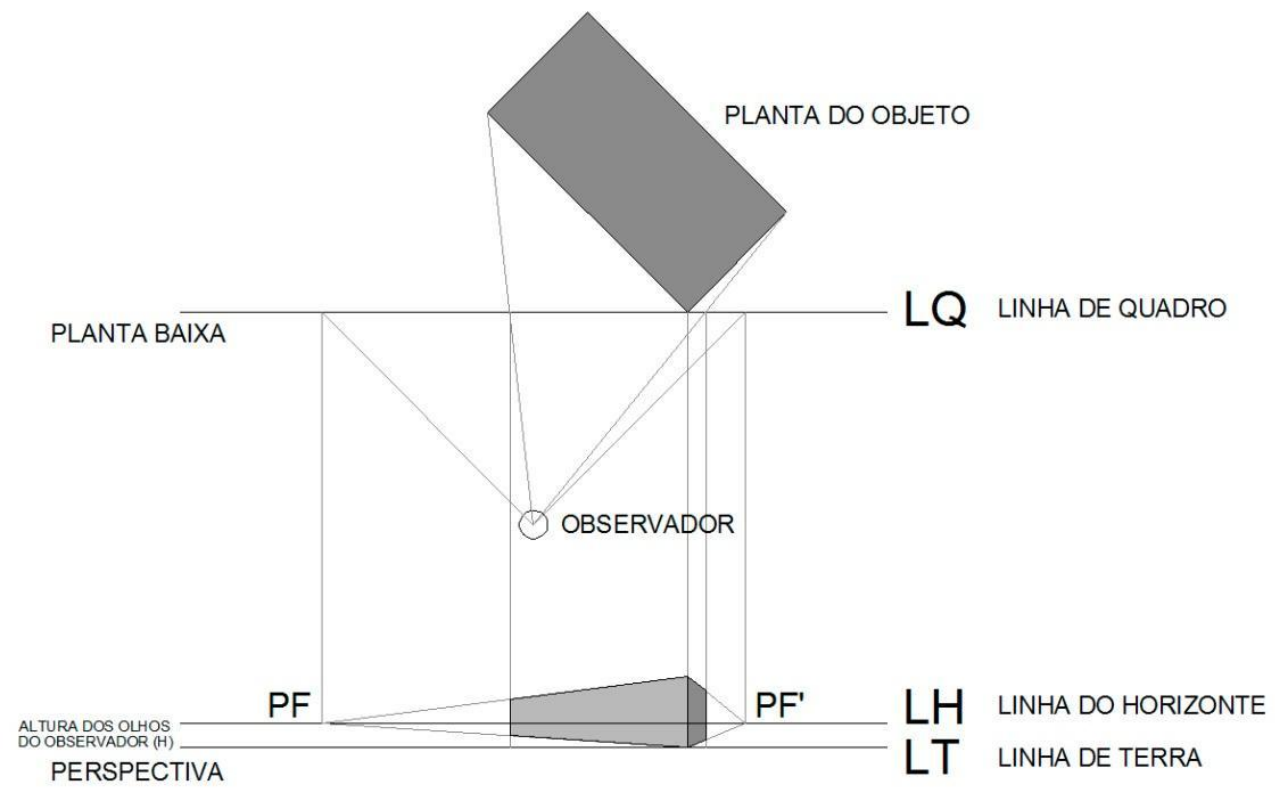

Montenegro (1999) destaca, no entanto, duas variações deste método, ambas com o objetivo de facilitar a localização das arestas afastadas da linha de quadro, exatamente as 
que tem sua posição deformada pelo escorço. A primeira, chamado 0 processo das 3 escalas, tem duas variações. Na primeira, quando a face do objeto representado está perpendicular à linha de quadro, é possível encontrar arestas afastadas da LQ atribuindo a medida desejada sobre a Linha de Terra e transferindo esta medida para a profundidade com o auxílio de um ponto de distância (D), que nada mais é do que o ponto de fuga correspondente à inclinação de 45으 em relação à linha de quadro. No caso de objetos que estejam inclinados em relação à $L Q$, o autor "força" o alinhamento utilizando uma linha imaginária perpendicular à linha de quadro, o eixo de profundidade, na qual todas as arestas são projetadas.

O que acontece, de fato, é que o método cria um triângulo isósceles em planta, com dois lados iguais e um ângulo de 45․ O autor faz questão de ressaltar que em faces perpendiculares à linha de quadro o desenho desse triângulo em planta é dispensável pois as medidas podem ser atribuídas diretamente sobre a LQ. No caso de objetos inclinados, entretanto, não há como fugir do desenho em planta uma vez que as medidas projetadas não são as reais, mas variáveis conforme o seno do ângulo formado com a linha de quadro.

A segunda variação é chamada $O$ processo dos medidores, que o autor faz questão de atribuir ao Professor Gastão Bahiana, do Rio de Janeiro, que a teria publicado em artigo no ano de 1927. Neste método, as medidas são atribuídas com o auxílio de um medidor (M), um ponto criado sobre a linha de quadro através da projeção do ponto de vista do observador (PV) sobre a linha de quadro. Essa projeção é dada com o auxílio do compasso, por um arco com centro da projeção do ponto de fuga sobre a linha de quadro (F) e raio igual a distância entre este e PV. Como no exemplo anterior, a medida da face do objeto é colocada sobre a linha de terra e transferida para a profundidade com o auxílio de um ponto, não mais o ponto $\mathrm{D}$, mas agora o ponto $\mathrm{M}$. Na realidade, como o próprio autor ressalta, este método é uma generalização do método anterior, sendo $D$ um caso particular de medidor para faces inclinadas 45으 em relação à linha de quadro. Quando essa inclinação é diferente de 45으, o triângulo resultante em planta não é mais um triângulo isósceles, mas um triângulo retângulo. O que o método faz, na realidade, é encontrar o ponto de fuga do ângulo que restaure este triângulo isósceles.

É certo que nem Monteiro nem Bahiana visavam construir um método de perspectiva que dispensasse o uso de instrumentos. $O$ uso da perspectiva em croquis é elaborado em uma série de outros livros, que abordam o problema de outra forma. Domingues (2011), por exemplo, recomenda para este fim o método de quadros em que se parte de uma LH e um ou dois pontos de fuga definidos arbitrariamente, preocupados não com a fidelidade de medidas mas com o melhor ajuste do desenho ao papel. A partir daí, embora siga com os pontos de fuga como referência, as técnicas em geral se baseiam muito mais no desenho de observação do que na perspectiva geométrica, não havendo menção à possibilidade da atribuição de medidas em profundidade. As únicas orientações neste sentido sugerem a utilização da linha do horizonte como referência para as medidas verticais. 


\section{METODOLOGIA}

- Levantamento e organização de todos os tipos de perspectiva geométrica existente através de revisão bibliográfica.

- Organização deste material apontando usos, características e vantagens de cada forma de representação.

- Familiarização com princípios básicos de geométrica descritiva: divisão de segmentos de reta, semelhança de triângulos e etc., que poderão ser úteis no desenvolvimento das novas técnicas.

- Análise detalhada dos métodos de traçado de perspectiva tradicionais, buscando atalhos e simplificações geométricas que não sacrifiquem sua precisão.

\section{RESULTADOS}

A partir dessas constatações, procurou-se desenvolver uma abordagem diferente para o ensino da perspectiva, ainda que fundamentada nos mesmos preceitos geométricos dos métodos apresentados por Montenegro (1999) e Domingues (2011). O método resultante não é propriamente novo, mas uma síntese, elaboração e refinamento dos anteriores, apresentando reais contribuições a eles.

A primeira preocupação foi em eliminar ao máximo o número de linhas no desenho, motivo de grande confusão e dificuldade. Para isso, uma atitude simples foi a sobreposição da linha do horizonte (LH) com a linha de quadro (LQ). Dessa forma, o posicionamento dos pontos de fuga pode ser feito com menos linhas. A sobreposição dos desenhos é um problema que será resolvido adiante.

Em seguida, a demarcação do observador também foi suprimida, e isso configura uma inversão importante no modo de pensar o desenho. Na realidade, a primeira função do observador no desenho é a de localizar os pontos de fuga conforme a sua distância do objeto. No entanto, este tipo de precisão é irrelevante para o tipo de desenho que estamos procurando e, portanto, abriremos mão dela em prol de um desenho mais ágil.

Sem a localização exata do observador diante do objeto, encontraremos diversos problemas a serem resolvidos. Em primeiro lugar, a localização precisa dos pontos de fuga na linha do horizonte (LH) depende da distância entre o observador e o objeto, bem como a localização em perspectiva das arestas que não tocam a linha de quadro.

Desses problemas, o primeiro será resolvido abrindo mão da precisão em favor da agilidade do desenho. Os pontos de fuga serão definidos arbitrariamente sobre a linha do horizonte, de preferência um de cada lado do papel. Se esses forem os pontos de fuga referentes às linhas que formam um ângulo de 45으 com o eixo de visão do observador (como é o caso das faces laterais do cubo de exemplo), eles devem ser equidistantes de um ponto de fuga que indica a posição do observador em relação ao objeto.

Neste ponto, a própria planta poderá ser suprimida do desenho. Daqui para frente, as arestas não serão mais encontradas a partir da planta, mas determinadas a partir da distância de outras arestas já desenhadas, todas elas, portanto, a partir da primeira. Em primeiro lugar, esta primeira aresta será posicionada a partir de sua distância horizontal com a posição do observador (d). No entanto, como suprimimos do desenho a linha de terra (LT), não temos condições de encontrar nem a posição e nem a altura da aresta segundo os métodos tradicionais. Adotaremos, a partir de agora, uma outra estratégia.

Já no início do desenho, o observador deve identificar a altura da linha do horizonte (LH), ou seja, a sua distância com uma linha de terra (LT) hipotética que foi suprimida do desenho. Feita essa definição, fica claro que teremos três situações distintas: se a altura da 
aresta for maior que a altura da linha do horizonte (LH), esta ultrapassará a linha do horizonte no desenho. Se for menor, ao contrário, a aresta não cruzará a linha do horizonte no desenho e, se a altura da aresta for a mesma da linha do horizonte, apenas tocará a linha do horizonte. Assim, nota-se que não podemos definir precisamente o comportamento de uma aresta que esteja acima ou abaixo da linha do horizonte, mas podemos definir precisamente uma aresta que apenas a toque como tendo uma altura equivalente à altura da linha do horizonte. Esta é a única medida que pode ser, por princípio, encontrada, e, portanto, será a referência para todas as demais a partir de agora.

Figura 2. Definição de arestas do mesmo tamanho, deformadas pela perspectiva.

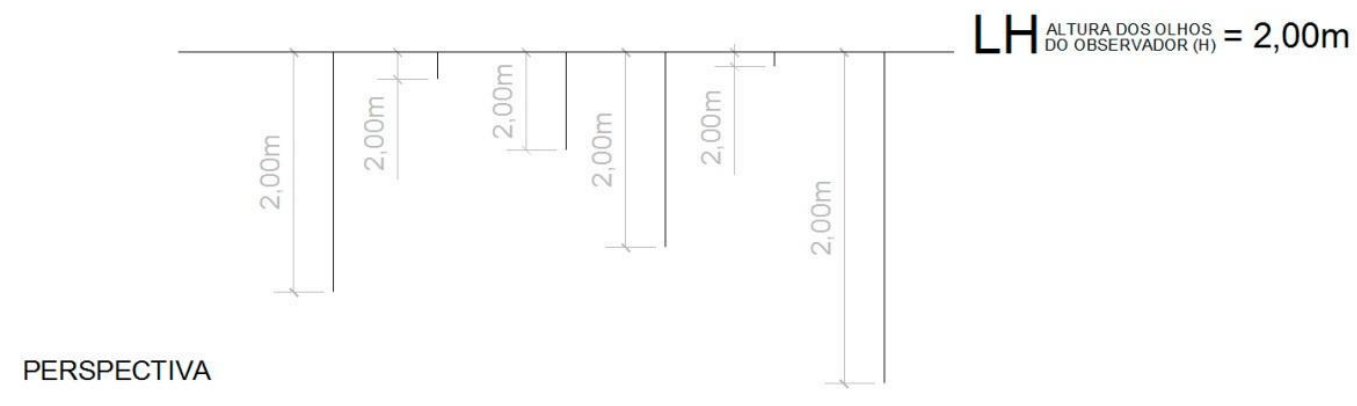

É importante notar que, a partir dessa primeira referência vertical, podemos encontrar qualquer outra medida através da proporção. Se a aresta que toca a linha do horizonte vale $2,00 \mathrm{~m}$, metade dela mesma valerá $1,00 \mathrm{~m}$ e o dobro valerá $4,00 \mathrm{~m}$, por exemplo. Este entendimento estava de certo modo implícito nas técnicas de desenhos em croquis apresentadas anteriormente, mas sua elaboração será fundamental para o problema da atribuição de medidas que deverá ser resolvido.

Encontradas as medidas verticais, as alturas, resta encontrar um modo de encontrar as medidas horizontais, largura e profundidade, dos objetos. Essas medidas podem ser divididas em quatro casos: no primeiro, a face do objeto encontra-se perpendicular ao eixo de observação, e este é o caso mais simples pois essa medida não será deformada pelo escorço. No segundo caso, as faces do objeto encontram-se paralelas ao eixo do observador e, no terceiro caso, as faces do objeto estão inclinadas a 450 em relação ao eixo do observador e, no último caso, em qualquer outra inclinação. Embora o último caso seja o de mais difícil resolução, é também o mais raramente utilizado para nossos propósitos.

No primeiro caso, encontrar medidas horizontais em faces perpendiculares ao eixo do observador é bastante simples. Como estas medidas não sofrem deformação por não terem ponto de fuga (ou terem um ponto de fuga localizado no infinito), basta transferir a medida da aresta vertical para a aresta horizontal.

No segundo caso, as medidas nas faces paralelas ao eixo do observador deformam-se conforme se afastam em profundidade. Trata-se do mesmo problema enfrentado por Montenegro (1999) no processo das 3 escalas, elaborado de forma ligeiramente diferente.

Como sabemos, essas faces se encaminham, no desenho, para um ponto de fuga localizado exatamente na frente do observador. Para encontrar medidas precisas neste eixo, recorreremos ao auxílio dos pontos de fuga relativos às faces de 45‥ Através de um procedimento geométrico simples e, baseando-se em um triângulo retângulo isósceles, basta transferir a medida desejada da aresta vertical para a horizontal perpendicular ao eixo 
de observação e a partir desse ponto encaminhar uma linha até o ponto de fuga das faces a 45 no lado oposto. O ponto de encontro entre essas linhas demarcará a transferência da medida desejada à face paralela ao eixo de observação.

Figura 3. Determinação de medidas horizontais em faces perpendiculares ao eixo de observação.
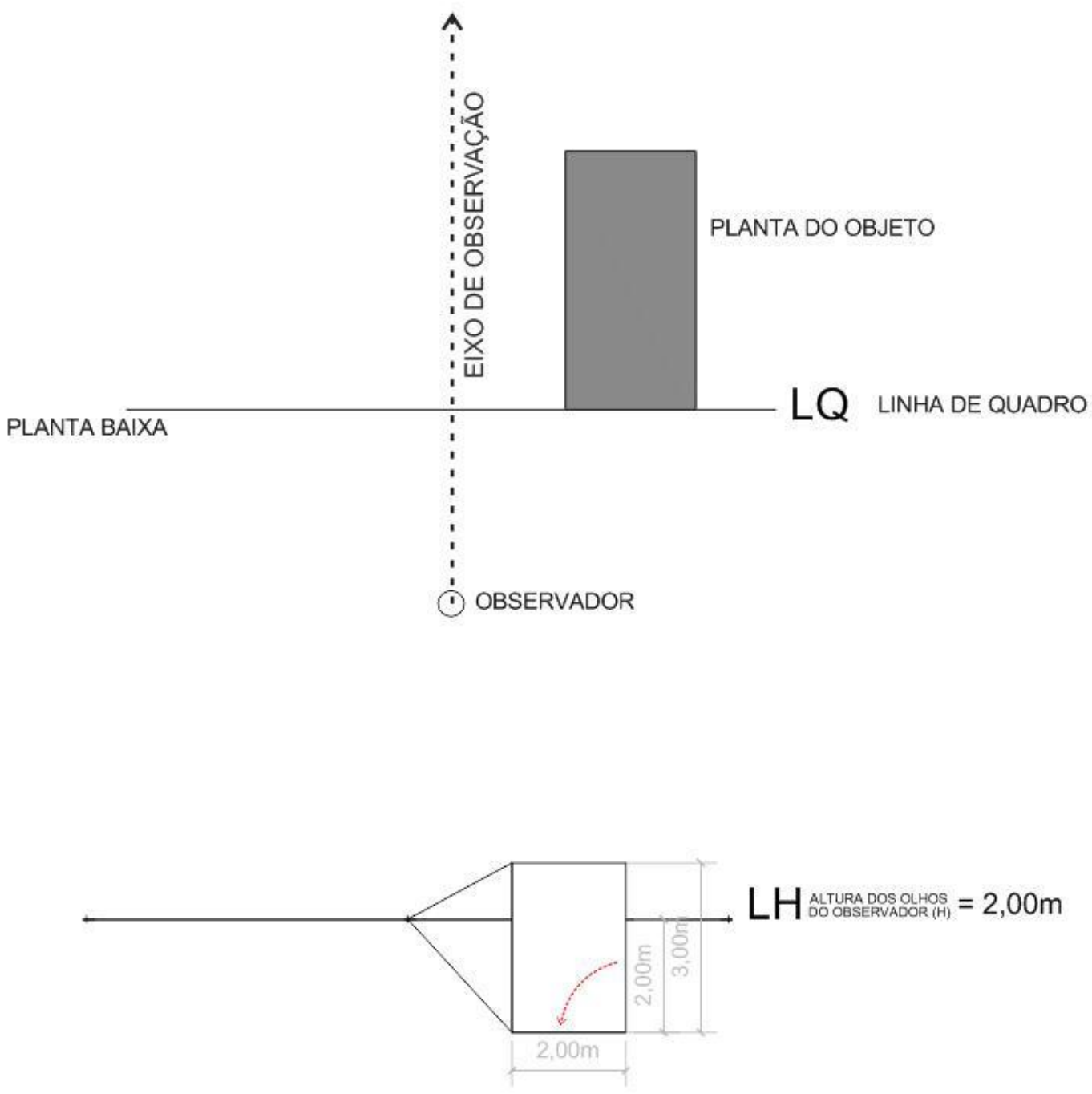

No terceiro caso, as medidas nas faces rotacionadas $45^{\circ}$ em relação ao eixo de observação podem ser encontradas de (pelo menos) dois modos. Além da técnica utilizada no 4을 caso, que também pode ser aplicada ao 3으, há ainda uma outra forma mais simples que pode ser aplicada especificamente a essas faces. De forma semelhante ao primeiro caso, deve-se transferir a medida vertical para esse eixo horizontal utilizando a bissetriz do ângulo formado entre a aresta vertical e uma linha que se direciona para o ponto de fuga correspondente.

Finalmente, para encontrar as medidas em faces em qualquer outra inclinação em relação ao eixo de observação, utilizamos o cosseno deste ângulo como um "correto de medidas", aplicado ao valor à medida encontrada na aresta vertical. 
Figura 4. Determinação de medidas em faces paralelas ao eixo de observação.
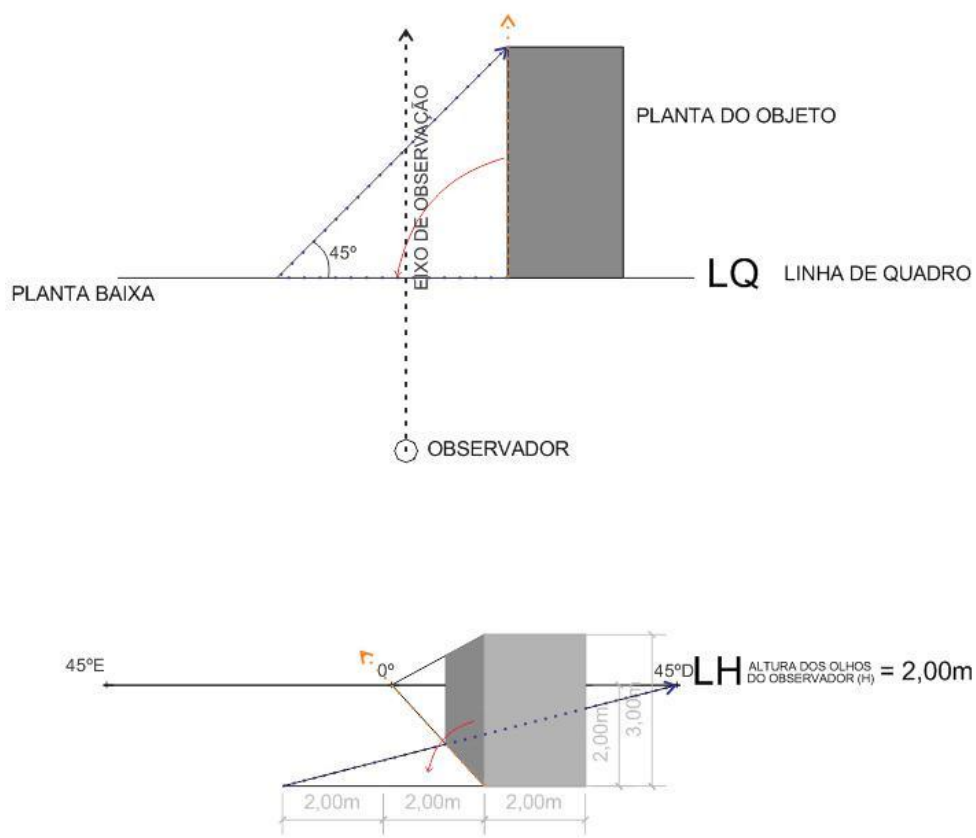

Figura 5. Determinação de medidas em faces rotacionadas a 45으 em relação ao eixo de observação.
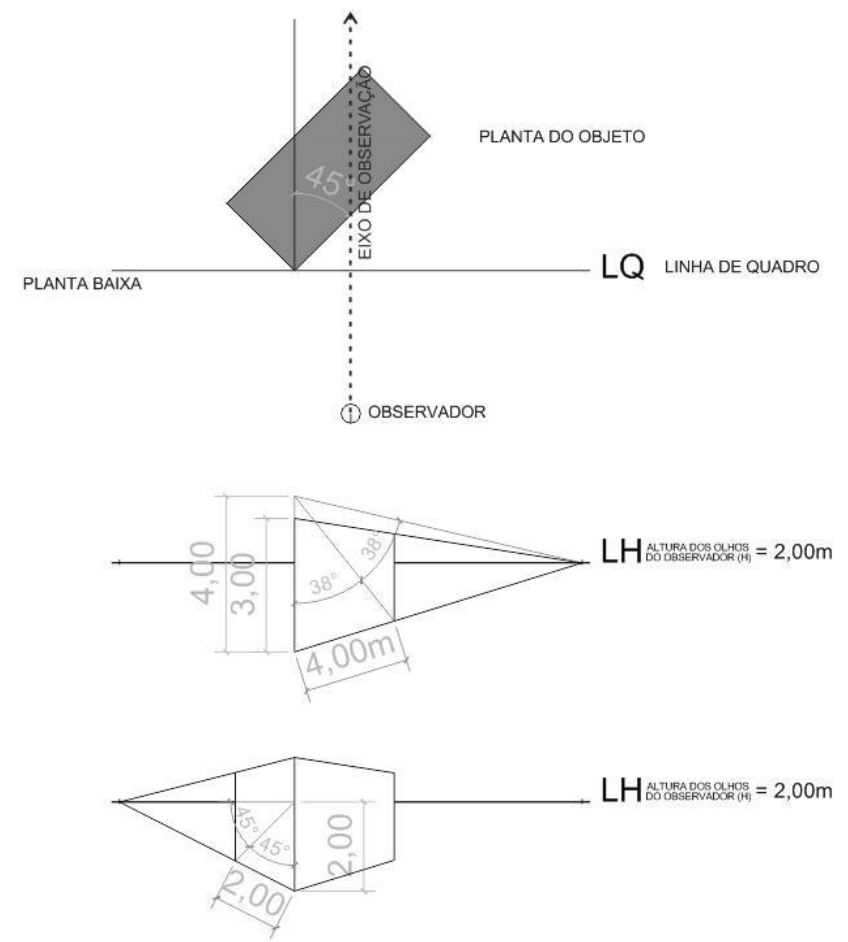


\section{DISCUSSÃO}

Embora este método libere em grande parte as mãos dos instrumentos de precisão, réguas, esquadros, escalímetros e compassos, é preciso também liberar a atenção para que a atividade criativa possa ser exercida plenamente. Para tanto, é bastante importante que, uma vez apreendidas as técnicas, a prática possa efetivar seu real domínio de modo que a atenção possa estar plenamente voltada ao desenvolvimento do projeto.

Outra constatação é o fato de que o escopo de estratégias pode ser adotado de forma diferente em diferentes momentos do desenho. Provavelmente, no momento de criação inicial, as proporções das arestas verticais sejam mais importantes enquanto as proporções horizontais podem ser apenas sugeridas sem grande precisão. Conforme o desenvolvimento do projeto, essa precisão pode ir sendo adicionada utilizando o mesmo conjunto de regras, dando versatilidade ao método.

\section{CONCLUSÃO}

O desenho em perspectiva constitui parte fundamental do projeto arquitetônico e é determinante para o domínio do espaço tridimensional. Assim, defendemos que seu ensino, estímulo e cobrança não se limite aos primeiros anos do curso de arquitetura e urbanismo, mas que seja firmemente trabalhado durante todo o curso até que, havendo o domínio das técnicas por parte do aluno, naturalmente ele fará uso da perspectiva por compreender sua importância.

\section{REFERÊNCIAS}

DOMINGUES, Fernando. Croquis e Perspectivas. Porto Alegre: Masquatro, 2011.

FROTA, Anésia Barros. Geometria da Insolação. São Paulo: Geros, 2004.

MONTENEGRO, Gildo A. A Perspectiva dos Profissionais. São Paulo: Edgard Blücher, 1981.

MONTENEGRO, Gildo A. Geometria Descritiva. São Paulo: E. Blucher, 1991.

SCHAARWÄCHTER, Georg. Perspectiva para arquitetos. Barcelona: G. Gili, 1976. 